\title{
Pulmonary pharmacokinetics of levofloxacin in rats after aerosolization of immediate-release chitosan or sustained-release PLGA microspheres
}

\author{
Marisa C. Gaspar ${ }^{\text {a,b,c }}$, Nicolas Grégoire ${ }^{\text {c,d }}$, João J.S. Sousa ${ }^{\mathrm{a}, \mathrm{b}}$, Alberto A.C.C. Pais ${ }^{\mathrm{e}}$, Isabelle Lamarche ${ }^{\mathrm{c}, \mathrm{d}}$, \\ Patrice Gobin ${ }^{\mathrm{c}, \mathrm{f}}$, Jean-Christophe Olivier ${ }^{\mathrm{c}, \mathrm{d}, *}$, Sandrine Marchand ${ }^{\mathrm{c}, \mathrm{d}, \mathrm{f}}$, William Couet $^{\mathrm{c}, \mathrm{d}, \mathrm{f}}$ \\ a Center for Neuroscience and Cell Biology, University of Coimbra, 3000-548 Coimbra, Portugal \\ b Laboratory of Pharmaceutical Technology, Faculty of Pharmacy, University of Coimbra, Pólo das Ciências da Saúde, Azinhaga de Santa Comba, 3000-548 Coimbra, Portugal \\ c INSERM, U 1070, Pôle Biologie Santé, 1 rue Georges Bonnet, TSA 51106, 86073 Poitiers Cedex 9, France \\ ' Université de Poitiers, Faculté de Médecine et Pharmacie, 6 rue de la Milétrie, TSA 51115, 86073 Poitiers Cedex 9, France \\ e Department of Chemistry, University of Coimbra, 3004-535 Coimbra, Portugal \\ ${ }^{\mathrm{f}}$ CHU Poitiers, 2 rue de la Milétrie, 86000 Poitiers, France
}

\section{A R T I C L E I N F O}

\section{Article history:}

Received 8 June 2016

Received in revised form 21 July 2016

Accepted 11 August 2016

Available online 13 August 2016

\section{Keywords:}

Microsphere

Sustained release

PLGA

Chitosan

Levofloxacin

Pulmonary pharmacokinetics

Pulmonary delivery

\begin{abstract}
A B S T R A C T
A comparative pharmacokinetic study was conducted in rats after intratracheal aerosolization of levofloxacin, as a solution, as immediate-release chitosan microspheres or as sustained-release PLGA microspheres. A pharmacokinetic model was constructed to model levofloxacin concentrations both in plasma and in the lung epithelial lining fluid (ELF). The plasma and ELF experimental concentration profiles versus time were similar for the intravenous and intratracheal levofloxacin solutions and for the intratracheal levofloxacin-loaded chitosan microsphere dry powder, indicating that levofloxacin diffused almost instantaneously through the broncho-alveolar barrier and that the chitosan microspheres released levofloxacin very rapidly, as anticipated from in vitro release studies. The bioavailability for the intratracheal levofloxacin solution and intratracheal chitosan microspheres was estimated to be $98 \%$ and $71 \%$, respectively, both with a direct release into the ELF compartment. The ELF-to-unbound plasma AUC ratios were slightly above 2 and may result from an efflux transport. For the intratracheal PLGA microspheres, a high ELF-to-unbound plasma AUC concentration ratio (311) was observed and high levofloxacin concentrations were maintained in ELF for at least $72 \mathrm{~h}$ in consistency with the in vitro release studies. The bioavailability was $92 \%$, with $19 \%$ of the dose released immediately (burst release) into the ELF and $73 \%$ released slowly into the ELF from a depot compartment, i.e. the PLGA microspheres, according to a Weibull model. These results highlight the benefit of using sustained-release microspheres administered as aerosols to provide and to maintain high pulmonary concentrations of an antibiotic characterized with a high permeability profile through the broncho-alveolar barrier. The sustained-release microsphere dry powder aerosol may therefore provide advantages over solutions or pure drug dry powders for inhalation in terms of treatment efficiency, ease of use and frequency of administration.
\end{abstract}

(c) 2016 Elsevier B.V. All rights reserved.

\section{Introduction}

The pulmonary administration of antibiotics as aerosols has gained increasing interest in the last years since it allows high lung concentrations, improving the antibacterial efficacy, and low systemic exposures, decreasing the toxicity (Hoppentocht et al., 2014). For Cystic Fibrosis lung disease, inhaled antibiotics represent alternatives to systemic oral or intravenous treatments in the prevention and management of Pseudomonas aeruginosa infections and several products have been marketed or are in the drug development pipeline (Gaspar et al., 2013). Levofloxacin solution for inhalation Quinsair ${ }^{\circledR}$ (in Europe, or

\footnotetext{
* Corresponding author at: INSERM, U 1070, Pôle Biologie Santé, 1 rue Georges Bonnet, TSA 51106, 86073 Poitiers Cedex 9, France.

E-mail address: jean.christophe.olivier@univ-poitiers.fr (J.-C. Olivier).
}

Aeroquin $^{\mathrm{TM}}$ in the USA) (Stockmann et al., 2014; Geller, 2009; Kirkby et al., 2011; Sawicki et al., 2012) promoted improvements in the lung function and lower systemic exposure, compared to oral and intravenous administrations (Foundation, 2015; EMA, 2015). Levofloxacin possesses a potent activity against Pseudomonas aeruginosa, even in the presence of the Cystic Fibrosis patients' sputum (King et al., 2010). Quinsair ${ }^{\circledR}$ requires relatively long administration times ( $5 \mathrm{~min}$ ) to deliver the therapeutic dose and fastidious hygienic procedures to clean the inhaler. In addition, being an immediate-release dosage form and due to the levofloxacin's high mucosal permeability (Koeppe et al., 2011) Quinsair ${ }^{\circledR}$ requires two administrations a day to maintain efficient levofloxacin concentrations in the lungs (EMA, 2015; Traini and Young, 2009). To overcome these inconveniences that preclude patients' comfort and compliance and in turn the levofloxacin treatment efficiency, a poly (lactide-co-glycolide) (PLGA) microsphere-based 
sustained-release dry powder formulation of levofloxacin is proposed in the present work. PLGA is a biocompatible and biodegradable polymer and was widely used in the synthesis of sustained release microspheres for inhaled therapy (Doan et al., 2011; Ramazani et al., 2015; Feng et al., 2014; Sah and Sah, 2015). Its biocompatibility and biodegradability (Anderson and Shive, 1997) is expected to minimize the impact on the lung function and accumulation, respectively. Microspheres were characterized in terms of pharmaceutical properties and a pharmacokinetic study was conducted in rats to assess systemic and pulmonary levofloxacin exposures after intratracheal aerosolization. For pharmacokinetic modeling and for comparison, the study included the intravenous administration or intratracheal aerosolization of a levofloxacin solution, as well as the intratracheal aerosolization of an immediate-release chitosan microsphere-based dry powder formulation (Gaspar et al., 2015).

\section{Materials and methods}

\subsection{Materials}

Resomer® RG 502 H (PLGA 50:50, acid terminated), dimethyl sulfoxide (DMSO) and chitosan of low molecular weight (20,000 cps, 75$85 \%$ deacetylated) were obtained from Sigma-Aldrich ${ }^{\circledR}$ (France). Rhodoviol 4/125 (polyvinylalcohol, degree of hydrolysis of $88 \%$ ) was purchased from Prolabo (France). Genipin (98\% purity) was obtained from Challenge Bioproducts Co., Ltd. (Taiwan). Levofloxacin hemihydrate was kindly provided by Tecnimede S.A. (Portugal). Isoflurane (Forène ${ }^{\circledR}$ ) was purchased from AbbVie (France). Dichloromethane BDH HipPerSolv ${ }^{\mathrm{TM}}$ for HPLC and formic acid 99-100\% AnalaR (NormaPur) were obtained from VWR ${ }^{\circledR}$ (France) and acetonitrile of HPLC grade was purchased from Carlo Erba reagents (France). All other chemicals were of analytical grade or equivalent. Purified water was produced using a MilliQ Gradient@ Plus Millipore system.

\subsection{Animals}

The animal experiments were conducted in compliance with EC Directive 2010/63/EU after approval by the local ethic committee (COMETHEA) and were registered by the French Ministry of Higher Education and Research under the authorization number 2015042116017243. Male Sprague Dawley® rats, RjHan:SD (300-400 g, 8-9 weeks of age) were obtained from Janvier Laboratories (Le Genest-St-Isle, France). They were housed in ventilated, temperature-controlled wire cages under a 12-h light-dark cycle for a minimum of 5 days before experiments, with ad libitum access to food (product reference: 4RF21-PF1610; FLASH Aptitude, Gif-sur-Yvette, France) and water. The same conditions were maintained after the drug administration.

\subsection{Methods}

\subsubsection{Preparation of the levofloxacin solution for intravenous administration}

On the day of the experiment, levofloxacin was dissolved in saline. The final concentration $(1.5-2 \mathrm{mg} / \mathrm{ml})$ was adapted to the rat weights in order to administer a maximum volume of $1 \mathrm{ml}$ through the tail vein and to achieve $5 \mathrm{mg}$ levofloxacin per $\mathrm{kg}$ body weight. This dose was calculated to be in the range of the levofloxacin inhalation solution (Aeroquin ${ }^{\circledR}$ ) doses administered in the Cystic Fibrosis patients (Geller et al., 2011).

\subsubsection{Preparation of the levofloxacin solution for intratracheal aerosolization}

On the day of the intratracheal administration, levofloxacin was dissolved in saline at a $20 \mathrm{mg} / \mathrm{ml}$ final concentration in order to administer a fixed volume of $100 \mu \mathrm{l}$ containing a targeted dose close to the intravenous dose $(5 \mathrm{mg} / \mathrm{kg})$.
2.3.3. Preparation of chitosan microspheres for intratracheal aerosolization Chitosan microspheres crosslinked with genipin and loaded with levofloxacin, were prepared by spray-drying and characterized as previously described (Gaspar et al., 2015). Briefly chitosan (0.5\% w/v) was added to $150 \mathrm{ml}$ of $1 \%(\mathrm{w} / \mathrm{v}$ ) acetic acid solution and allowed to dissolve under magnetic stirring (300 rpm) at $50{ }^{\circ} \mathrm{C}$ for $3 \mathrm{~h}$, then at room temperature overnight. The obtained solution was paper-filtered and after addition of levofloxacin $(750 \mathrm{mg})$ the preparation was stirred for $30 \mathrm{~min}$. Then, genipin $(0.2 \mathrm{mmol}$ per $\mathrm{g}$ chitosan) was added and the crosslinking reaction was performed at $50{ }^{\circ} \mathrm{C}$ for $3 \mathrm{~h}$ under magnetic stirring (300 rpm). The mixture was spray dried using a Büchi® Mini Spray Dryer B-290 (Switzerland) set up in the blowing mode and equipped with a $0.7 \mathrm{~mm}$ nozzle. Settings were: $10 \mathrm{ml} / \mathrm{min}$ pump rate, $473 \mathrm{l} / \mathrm{h}$ air flow rate, $100 \%$ aspiration rate, and inlet temperature of $120{ }^{\circ} \mathrm{C}$ (outlet temperature: $45-60{ }^{\circ} \mathrm{C}$ ). The drug content determined by HPLC was $48.4 \pm 5.8 \mathrm{wt} . \%$ and the mass median aerodynamic diameter (MMAD) of the microsphere powder emitted with a Handihaler ${ }^{\circledR}$ Dry Powder Inhaler (DPI) was determined to be $5.4 \pm 0.2 \mu \mathrm{m}$ using a Next Generation Impactor (NGI, Copley Ltd., Nottingham, UK). In vitro release studies showed $>90 \%$ release within $15 \mathrm{~min}$ in phosphate buffered saline (PBS), $\mathrm{pH} 7.4$ at $37^{\circ} \mathrm{C}$.

\subsubsection{Preparation of the PLGA microspheres}

Levofloxacin-loaded PLGA microspheres were prepared by a double emulsion-solvent evaporation method with premix membrane homogenization (Doan et al., 2011). Briefly, $0.6 \mathrm{ml}$ of a levofloxacin solution ( $250 \mathrm{mg} / \mathrm{ml}$, adjusted to $\mathrm{pH} 6$ with hydrochloric acid) was emulsified into $3 \mathrm{ml}$ of a solution of PLGA (300 mg) and levofloxacin (100 mg) in dichloromethane using a Polytron ${ }^{\circledR}$ PT 3100 D homogenizer equipped with a $7 \mathrm{~mm}$ homogenizing accessory (Kinematica AG, Switzerland) and set at 30,000 rpm for $30 \mathrm{~s}$. The obtained $\mathrm{W}_{1} / 0$ emulsion was dispersed in $7 \mathrm{ml}$ of a solution $\mathrm{W}_{2}$ of polyvinylalcohol $(3 \% \mathrm{w} / \mathrm{v})$ saturated with levofloxacin $(35 \mathrm{mg} / \mathrm{ml})$ in PBS at $\mathrm{pH} 7.4$ under magnetic stirring (400 rpm). The resulting $\mathrm{W}_{1} / 0 / \mathrm{W}_{2}$ emulsion was subjected to three homogenization cycles through a Shirasu porous glass membrane (19.9 $\mu \mathrm{m}$ porosity) under $25 \mathrm{kPa}$ transmembrane pressure using an external pressure-type micro kit emulsification device (SPG Technology, Sadowara, Japan). It was immediately poured into $25 \mathrm{ml}$ of a solution of $0.4 \%(\mathrm{w} / \mathrm{v})$ polyvinylalcohol saturated with levofloxacin $(32 \mathrm{mg} / \mathrm{ml}$ ) in PBS under magnetic stirring (400 rpm). Dichloromethane was evaporated off under vacuum at room temperature during 10 min using a rotary evaporator. Microspheres were washed through three cycles of centrifugation (2200g, $5 \mathrm{~min})$, resuspended in purified water $(2 \mathrm{ml})$ and freeze-dried.

\subsubsection{Characterization of the PLGA microspheres}

The mean size of the volume distribution $\left(D_{v}\right)$ of microspheres was determined in purified water using laser light diffraction (Microtrac ${ }^{\circledR}$ X100 particle size analyzer) as previously (Doan et al., 2011; Doan and Olivier, 2009). Yield (\%) was calculated from the recovered mass of freeze-dried microspheres versus the initial weight of levofloxacin (in $\mathrm{O}$ and $\mathrm{W}_{1}$ phases) plus PLGA. The microsphere drug content (\%), i.e. the amount of levofloxacin ( $\mathrm{mg}$ ) per $100 \mathrm{mg}$ of microspheres (including entrapped levofloxacin), was determined by spectrophotometry at 300 nm using a Varian Cary 50 UV-Visible spectrophotometer after dissolution in DMSO using a levofloxacin calibration curve $(0.625-10 \mu \mathrm{g} /$ $\mathrm{ml}$ concentration range in DMSO). MMAD was determined with a Handihaler ${ }^{\circledR}$ Dry Powder Inhaler (DPI) using a Next Generation, as previously described (Gaspar et al., 2015). The powder remaining in the capsule and deposited in the inhaler, induction port and all the stages was collected with DMSO for levofloxacin spectrophotometric determination. Microspheres were examined by scanning electron microscopy (SEM) using a Jeol JSM 6010 LV electron microscope (Tokyo, Japan) at $15 \mathrm{kV}$, after gold-sputtering the microspheres in an argon atmosphere. For in vitro release studies under sink conditions, levofloxacin-loaded microspheres ( $5 \mathrm{mg}$ ) were dispersed in $10 \mathrm{ml}$ of PBS, pH 7.4, and 
incubated at $37{ }^{\circ} \mathrm{C}$ under magnetic stirring (600 rpm) (Gaspar et al., 2015). One milliliter aliquots were collected at pre-determined time points over 7 days and centrifuged at $1900 \mathrm{~g}$ for 5 min (Hettich ${ }^{\circledR}$ Zentrifugen Universal 320R, Germany). Then, $100 \mu$ of supernatant were collected and levofloxacin determined by HPLC, as previously described (Gaspar et al., 2015). The remaining $900 \mu$ were vortex-mixed and added back to the flasks.

\subsubsection{Pharmacokinetic study}

The targeted levofloxacin dose was $5 \mathrm{mg}$ per kg body weight. The rats $(n=80)$, divided in four groups, were anaesthetized with inhaled isoflurane before dosing. Group $1(n=15)$ received an intravenous bolus injection of a levofloxacin solution in saline in a tail vein. Group $2(\mathrm{n}=15)$ was treated intratracheally with aerosolized $20 \mathrm{mg} / \mathrm{ml}$ levofloxacin solution in saline $(100 \mu \mathrm{l})$ using a IA-1C liquid Microsprayer ${ }^{\circledR}$ Aerosolizer (Penn-Century Inc., Philadelphia, USA), as previously described (Marchand et al., 2010). The immediate-release chitosan microspheres ( $4 \mathrm{mg}$, corresponding to $2 \mathrm{mg}$ of levofloxacin, Group 3, $n=15$ ) or the sustained release PLGA microspheres (20 mg, corresponding to $2 \mathrm{mg}$ levofloxacin, Group $4, \mathrm{n}=35$ ) were aerosolized intratracheally using a Dry powder Insufflator ${ }^{\mathrm{TM}}$ DP-4 (Penn-Century Inc., Philadelphia, USA), device that was weighed before and after the administration in order to measure the actual administered dose. To perform the intratracheal administrations, anaesthetized rats were placed on a rodent work stand inclined at an angle of $45^{\circ}$ (Tem, Lormont, France) and the tip of the microsprayer or of the powder insufflator was introduced into the rat's trachea with visualization of the vocal cords using an otoscope (Gagnadoux et al., 2005). After the intravenous or the intratracheal aerosol administrations, rats were returned to individual cages with free access to food and water. At pre-determined time points, rats ( 3 to 5 per time point) were re-anaesthetized with inhaled isoflurane for broncho-alveolar lavage (BAL) and blood sampling. After rat immobilization in a supine position with cervical hyperextension, the trachea was exposed and incised between two rings. A polyethylene catheter $(0.58 \mathrm{~mm}$ i.d. and $0.96 \mathrm{~mm}$ o.d.; Harvard, Les Ulis, France) connected to a syringe filled with $1 \mathrm{ml}$ of saline at $37{ }^{\circ} \mathrm{C}$ was inserted into the trachea ( $50 \mathrm{~mm}$ deep). After injection of saline, BAL samples ( 300 to $800 \mu \mathrm{l}$ ) were immediately collected by aspiration via the same catheter. A blood sample was then collected by cardiac puncture. BAL and blood samples were centrifuged (at $1900 \mathrm{~g}$ for $5 \mathrm{~min}$ and at $1400 \mathrm{~g}$ for $10 \mathrm{~min}$, respectively, at $4{ }^{\circ} \mathrm{C}$ ) and supernatants stored at $-20{ }^{\circ} \mathrm{C}$ until levofloxacin and urea assays. For BAL sampling, conditions for centrifugation were optimized in a preliminary study in order to ensure that all the PLGA microspheres potentially withdrawn during the BAL procedure were sedimented. ELF levofloxacin concentrations, $\mathrm{C}_{\mathrm{ELF}}$, were estimated from the BAL sample levofloxacin concentrations $\left(C_{B A L}\right)$ using a dilution factor calculated from the urea concentrations in plasma (Urea plasma ) and in BAL (Urea BAL $_{\text {L }}$ ) samples using the equation $\mathrm{C}_{\mathrm{ELF}}=\mathrm{C}_{\mathrm{BAL}}\left(\right.$ Urea $_{\text {plasma }} /$ Urea $_{\mathrm{BAL}}$ ) (Gontijo et al., 2014).

\subsubsection{Levofloxacin determination}

2.3.7.1. Sample preparation. For plasma samples, $50 \mu \mathrm{l}$ of plasma were mixed with $200 \mu \mathrm{l}$ of the ciprofloxacin internal standard solution $(0.1 \mu \mathrm{g} / \mathrm{ml})$ in acetonitrile. Protein precipitate was separated by centrifugation at $14,200 \mathrm{~g}$ for $15 \mathrm{~min}$ and $200 \mu \mathrm{l}$ of supernatant were collected and vortex-mixed with $400 \mu \mathrm{l}$ of $0.1 \%(\mathrm{v} / \mathrm{v})$ formic acid prior to analysis. The same procedure was applied to levofloxacin calibration standards ( 2 to $400 \mathrm{ng} / \mathrm{ml}$ ) prepared in blank rat plasma samples. For BAL samples, $20 \mu \mathrm{l}$ of supernatant were mixed with $80 \mu \mathrm{l}$ of ciprofloxacin internal standard solution $(0.05 \mu \mathrm{g} / \mathrm{ml})$ in $0.1 \%(\mathrm{v} / \mathrm{v})$ formic acid before analysis. For BAL sample analysis, levofloxacin calibration standards (2 to $400 \mathrm{ng}$ / $\mathrm{ml}$ ) were prepared in saline.
2.3.7.2. Liquid chromatography tandem-mass spectrometry (LC-MS/MS). Levofloxacin concentrations were determined in plasma and BAL samples using a validated LC-MS/MS method. The system consisted of a Waters Alliance 2695 separations module equipped with a binary pump and an autosampler thermostatically controlled at $4{ }^{\circ} \mathrm{C}$, and of a Waters Micromass ${ }^{\circledR}$ Quattro micro API triple quadrupole tandem mass spectrometer. Reversed-phase chromatography was performed on a Phenomenex Jupiter ${ }^{\mathrm{TM}} \mathrm{C} 18300$ Á column $(5.0 \mu \mathrm{m}, 50 \times 2.1 \mathrm{~mm})$. The mobile phase was composed of $0.1 \%(\mathrm{v} / \mathrm{v})$ formic acid in acetonitrile and $0.1 \%(\mathrm{v} / \mathrm{v})$ formic acid in water $(25: 75(\mathrm{v}: \mathrm{v}))$. The flow rate was $0.20 \mathrm{ml} / \mathrm{min}$ and the injection volume $20 \mu \mathrm{l}$. The mass spectrometer was operated in the positive-ion mode. Ions were analyzed via multiple reaction monitoring (MRM) employing the transition of the $[\mathrm{M}+2 \mathrm{H}]^{2+}$ precursor to the product ions for the analyte and for the internal standard. Transition ions were 362.2 to $318.2 \mathrm{~m} / \mathrm{z}$ for levofloxacin and 332.2 to $314.2 \mathrm{~m} / \mathrm{z}$ for the internal standard. Optimal MS/MS set up parameters were: $+3.25 \mathrm{kV}$ ion spray voltage, $600 \mathrm{~L} / \mathrm{h}$ and $350{ }^{\circ} \mathrm{C}$ desolvation gas $\left(\mathrm{N}_{2}\right)$ flow and temperature respectively, $10 \mathrm{~L} / \mathrm{h}$ cone gas $\left(\mathrm{N}_{2}\right)$ flow, $120^{\circ} \mathrm{C}$ source temperature, $25 \mathrm{~V}$ cone potential for the analyte and for the internal standard, $20 \mathrm{~V}$ collision energy for the analyte and the internal standard, $500 \mathrm{~ms}$ dwell time.

The lower limit of quantification (LLOQ) for levofloxacin determinations in plasma and BAL samples was $2 \mathrm{ng} / \mathrm{ml}$, and no experimental measurements were outside the standard curves (2 to $400 \mathrm{ng} / \mathrm{ml}$ ). Intra- and interday variabilities were characterized at four concentration levels (including LLOQ) with precision and accuracy lower than $15 \%$ for 400,40 , and $5 \mathrm{ng} / \mathrm{ml}$ concentrations and lower than $20 \%$ for the LLOQ.

\subsubsection{Urea determination}

For urea determination in plasma, a photometric detection was applied using a modular automatic analyzer (Roche, France). The urea concentration in BAL samples was evaluated by LC-MS/MS, as previously described (Gontijo et al., 2014).

\subsubsection{Pharmacokinetic analysis and modeling strategy}

Levofloxacin plasma concentrations versus time data were analyzed according to a non-linear mixed effects method with S-ADAPT software (v 1.52) using MC-PEM (Monte-Carlo Parametric Expectation Maximization) estimation algorithm and S-ADAPT TRAN translator (Bulitta et al., 2011). Observed concentrations were log-transformed for the analysis. Various structural models were tested and compared based on the likelihood ratio tests $(\mathrm{p}<0.05)$ of their objective functions and on visual inspection of diagnostic plots. The structural pharmacokinetic model (Fig. 1) was derived from an initial generic hybrid compartment model, with a mono-compartmental model for the systemic pharmacokinetics and a bi-compartment model for the ELF pharmacokinetics. The model for levofloxacin systemic pharmacokinetics was monocompartmental with a distribution volume $\mathrm{Vd}$ and a total clearance CL. The distribution between plasma and ELF was described by two different processes, on the one hand by a bi-directional transfer characterized by a clearance $\mathrm{Cl}_{\text {dif }}$ and on the other hand by a unidirectional transfer from plasma to ELF characterized by a clearance $\mathrm{Cl}_{\text {out }}$. Only the unbound fraction of levofloxacin in plasma (55\%) (Hurtado et al., 2014) was assumed to distribute between plasma and ELF. A bi-compartmental pharmacokinetics of levofloxacin in the ELF was necessary for a good fitting of the observed data, with the ELF compartment characterized with a volume $V_{\text {ELF }}$ estimated by the modeling and directly linked to the plasma compartment, and a peripheral compartment of volume $V_{p}$ characterized with a distribution clearance $\mathrm{Cl}_{\text {dist }}$. Both $\mathrm{V}_{\mathrm{ELF}}$ and $\mathrm{V}_{\mathrm{p}}$ were estimated through modeling. For a good fitting of the ELF concentrations the release process of levofloxacin from the intratracheally-aerosolized formulations was divided into two components: a fraction of the dose $\mathrm{F}_{\mathrm{ELF}}$ that was immediately released into the ELF compartment (burst release), and a fraction of the dose $F_{\text {Weib }}$ that was released 


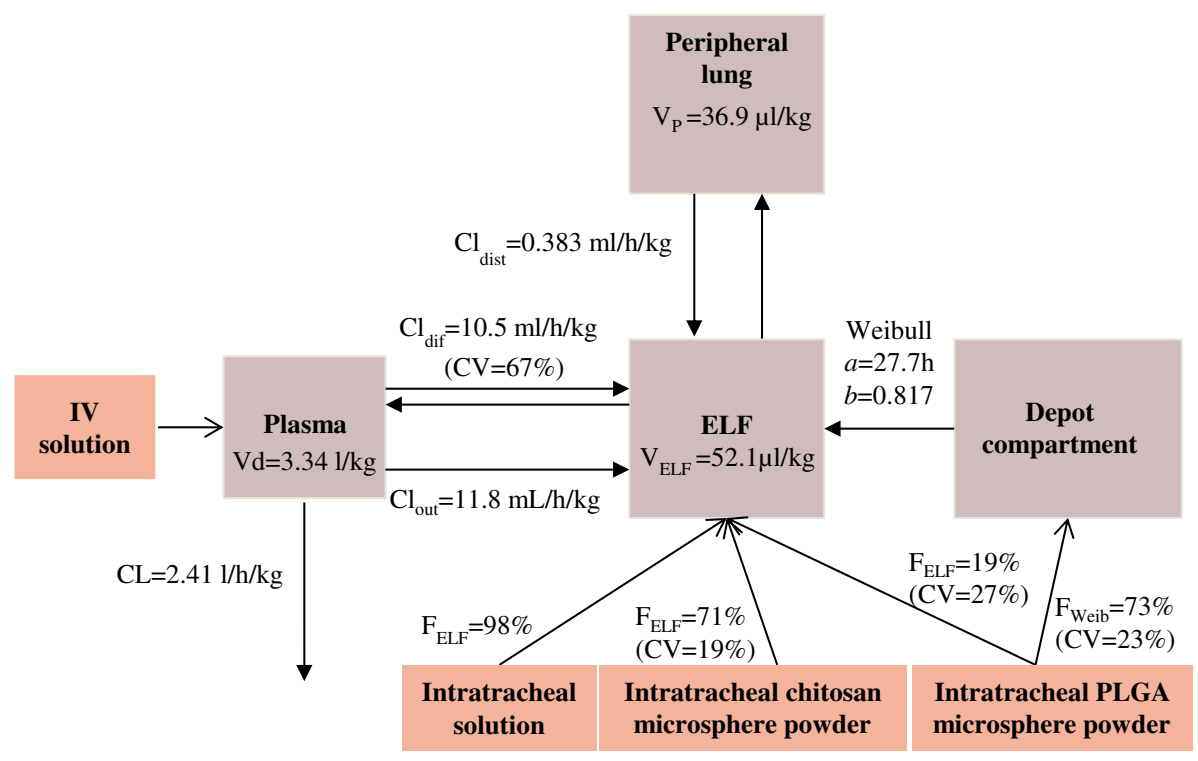

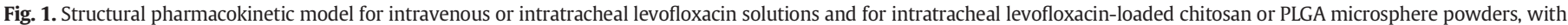

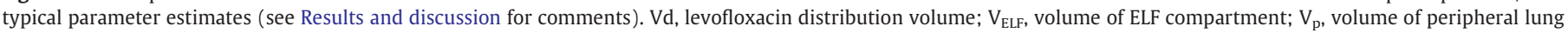

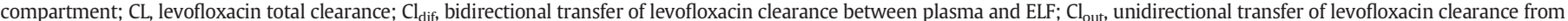

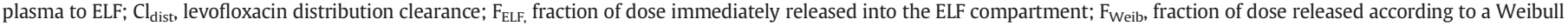
release model; $a$, time scale parameter; $b$, curve shape parameter, and $\mathrm{CV}$, estimable inter-individual variabilities.

according to a Weibull release model as previously described (Doan et al., 2013), expressed as a differential equation for pharmacokinetic modeling,

$\frac{d \mathrm{Q}}{d t}=\mathrm{Q} \times\left(\frac{b}{a}\right) \times\left(\frac{t}{a}\right)^{(b-1)}$

where $Q$ is the amount of levofloxacin not yet released, $t$ is time, $a$ is the time-scale parameter and $b$ the shape parameter. Inter-individual variabilities were expressed as coefficient of variation (CV) and modeled as log-normal. The residual variability was estimated with an additive error model on the log scale, back-transformed into a proportional error model on normal scale for both plasma and ELF data. Plasma drug concentrations below the LLOQ were handled using the Beal M3 method (Beal, 2001).

\section{Results and discussion}

\subsection{PLGA microsphere characterization and in vitro levofloxacin release profile}

The double emulsion-solvent evaporation method with premix membrane homogenization produced narrowly size-distributed PLGA microspheres with a mean volume hydrodynamic diameter $D_{v}=$ $5.0 \pm 1.7 \mu \mathrm{m}$ and a yield of $50.0 \pm 4.9 \mathrm{wt} . \%$. The drug content of $10.5 \pm 1.4 \mathrm{wt}$.\% was considered satisfactory taking into account that highly water soluble drugs, such as levofloxacin, are generally poorly entrapped within the hydrophobic PLGA polymer matrix (Govender et al., 1999). The SEM of the freeze-dried PLGA microsphere powder showed spherical particles with a smooth and poreless surface (Fig. $2 \mathrm{~A}$ and $\mathrm{B}$ ) though some small surface features were visible and attributed to residual polyvinylalcohol (Fig. 2B).

Using the Handihaler ${ }^{\circledR}$ DPI to aerosolize the powder, the MMAD was $7.1 \pm 0.2 \mu \mathrm{m}$, and the fine particle fraction (FPF) was $30.2 \pm 2.3 \%$. The fact that MMAD was slightly higher than $D_{v}$ was attributed to microspheres aggregation, as shown by SEM (Fig. 2A). In PBS at $37^{\circ} \mathrm{C}$, under sink conditions, the levofloxacin release (Fig. 3 ) was characterized by a "burst" release of $40 \%$ of the levofloxacin microspheres content within the first $30 \mathrm{~min}$, followed by a gradual release up to at least $72 \mathrm{~h}$. At $72 \mathrm{~h}$, approximately $75 \%$ of the drug content was released. After 1 week in
PBS at $37^{\circ} \mathrm{C}$ (Fig. 2C and D), the microspheres appeared to be extensively degraded with obvious signs of surface alteration (Fig. 2D) in agreement with previous works (Díez and Tros de Ilarduya, 2006), while $25 \%$ of levofloxacin initial content still remained in the microsphere polymer matrix (not shown). The low molecular weight PLGA 50:50 Resomer ${ }^{\circledR} 502 \mathrm{H}$ is therefore expected to minimize pulmonary accumulation of polymer after microsphere lung deposition, especially in the case of repeated administrations.

\subsection{Pharmacokinetic experimental and model-predicted results}

The administration of intravenous and intratracheal levofloxacin solutions as well as intratracheal chitosan or PLGA microsphere powders to the rats did not cause apparent signs of toxicity. The rats that were maintained up to $72 \mathrm{~h}$ after the intratracheal treatment with aerosolized PLGA microspheres showed normal weight gain. Through the intravenous route, rats were dosed accurately with $5 \mathrm{mg}$ levofloxacin per $\mathrm{kg}$ body weight, but through the intratracheal route, due to the fixed volume of liquid administered with the microsprayer or the variable dosing efficiency of the powder insufflator, the targeted levofloxacin dose was not achieved and actual doses are presented in Table 1.

A population pharmacokinetic approach was used to characterize mainly the intra-pulmonary pharmacokinetics of levofloxacin after intratracheal aerosolization of the two dry microsphere powder formulations. The study design included the intravenous and intratracheal administrations of a levofloxacin solution in order to get comparators and to improve the modeling output since the population pharmacokinetic approach allows simultaneous analysis of various data sets. It is also the most appropriate modeling procedure when only one data set (i.e., simultaneous plasma and ELF concentrations) can be collected in each individual. The pharmacokinetic model is presented with the pharmacokinetic parameter estimates on Fig. 1. No inter-individual variability could be estimated for CL, Vd and $V_{p}$. Eventually, the selected pharmacokinetic model provided a reasonably good description of the experimental data over time, both in plasma and ELF, after intravenous administration or intratracheal aerosolization with the various formulations, as illustrated on Fig. 4. Residual errors of the model were $13 \%$ in plasma and $18 \%$ and $21 \%$ in ELF depending on whether levofloxacin was administered intravenous or intratracheal (all formulations taken 

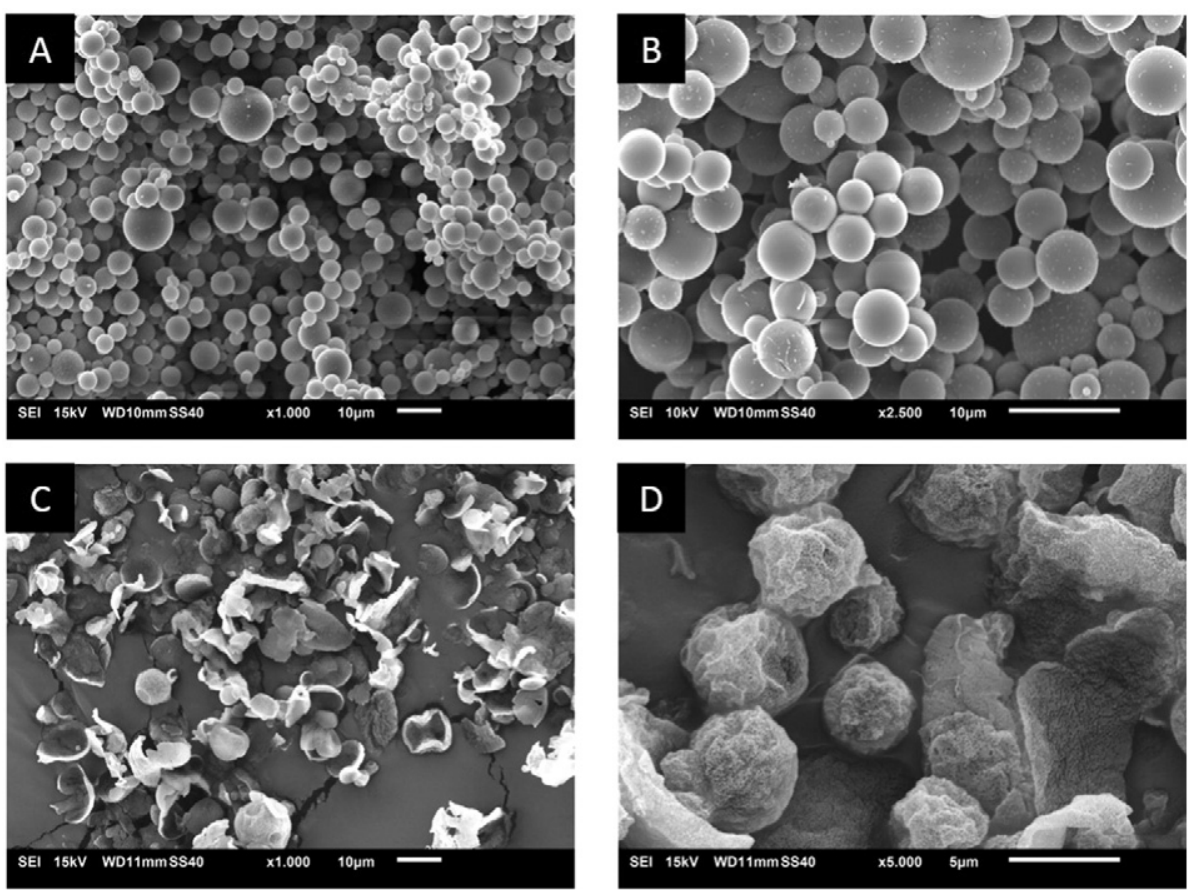

Fig. 2. SEM images of PLGA microspheres after preparation (A and B) and after a one-week incubation at $37^{\circ} \mathrm{C}$ in $\mathrm{PBS} \mathrm{pH} 7.4$ under a 600 -rpm magnetic stirring (C and $\mathrm{D}$ ).

together), respectively. The much higher ELF exposure after levofloxacin-loaded PLGA microsphere aerosolization with high concentrations sustained over time was adequately reported by the model. However, the analysis of the pharmacokinetic study needs to take into account some limitations. Rapid initial absorption or distribution phases are often difficult to characterize in pharmacokinetics, especially when sampling procedures are not instantaneous (which is the case of the BAL sampling method). Early ELF concentrations after intratracheal aerosolization of the dry microsphere powders may indeed depend on multiple uncontrolled parameters, including the depot characteristics and the onset of drug release from the microspheres or/and of levofloxacin solubilization within the small volume of the ELF (Fig. 1). In addition, the invasive intratracheal aerosolization procedure may induce by itself a transient alteration of the lung physiology which may affect levofloxacin disposition. All these factors would

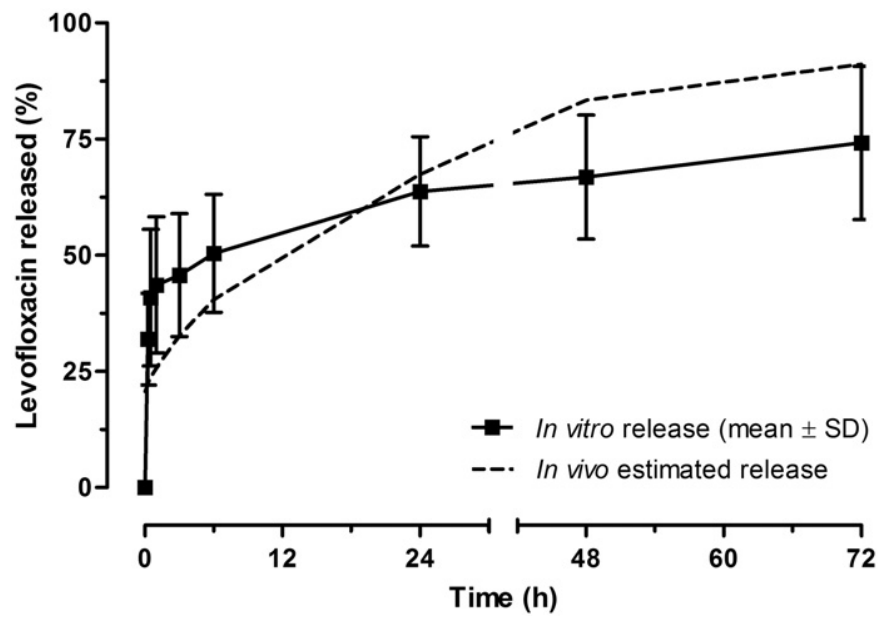

Fig. 3. Experimental in vitro release data of levofloxacin-loaded PLGA microspheres in PBS, $\mathrm{pH} 7.4$, at $37^{\circ} \mathrm{C}$ (mean $\pm \mathrm{SD}$ (square), $\mathrm{n}=3$ ). Also represented is the in vivo release kinetic curve (dashed line) predicted by the pharmacokinetic model after intratracheal administration of PLGA microspheres and cumulating the immediate release $\left(\mathrm{F}_{\mathrm{ELF}}=\right.$ $19 \%$ of administered dose) and the slow release according to a Weibull model ( $F_{\text {Weib }}=$ $73 \%, a=27.7 \mathrm{~h}$ and $b=0.817$ ) result in a high variability of the data at early sampling times, which would require extensive data, therefore a large number of animals, in order to interpret properly and to computerize the initial resorption and distribution phases. Therefore, it was decided not to collect plasma and BAL samples earlier than 30 min post-administration. As a consequence, the pharmacokinetic model with an early burst release is probably a crude description of a more complex reality and the very high initial ELF concentrations of levofloxacin predicted by the model (between $20 \mathrm{mg} / \mathrm{ml}$ and $100 \mathrm{mg} / \mathrm{ml}$, depending on the administered formulation), together with the ELF AUC between time 0 and $0.5 \mathrm{~h}$ which contributed dramatically to the total AUC should be taken with caution. Accordingly, AUC from 30 min to the last time of measurable concentration $\left(\mathrm{AUC}_{0.5}-\mathrm{t}\right)$ were considered in order to compare levofloxacin exposures (Table 1 ).

Intratracheal or intravenous administration of the levofloxacin solutions resulted in similar experimental levofloxacin concentrations in plasma and ELF (Fig. 4a and b) with an elimination half-life of $0.96 \mathrm{~h}$. The bioavailability for the intratracheal solution was estimated to be $98 \%$, with a direct release of levofloxacin into the ELF compartment. The distribution between the ELF and plasma compartments was very rapid, with an estimated half-life of transfer between the two compartments lower than $1 \mathrm{~min}$. The estimated levofloxacin passive diffusion clearance $\mathrm{Cl}_{\text {dif }}$ (Fig. 1) was close to the value determined for moxifloxacin (Gontijo et al., 2014), in consistency with their close log D values (Brillault et al., 2010) and their reported high permeability (Saelim et al., 2015). For both routes of administration of the levofloxacin solutions, the ELF-to-plasma $\mathrm{AUC}_{0.5}-72 \mathrm{~h}$ ratios were slightly above 1 . The $\mathrm{Cl}_{\text {out }}$ term which improved the modeling reflected the higher ELF levofloxacin concentrations than the levofloxacin unbound plasma concentrations, independently of the route of administration. It is of note that the ELF-to-plasma $\mathrm{AUC}_{0.5}-\mathrm{t}$ ratio is slightly above 2 when considering unbound concentrations in plasma, which reflected the ratio of the plasma-to-ELF clearances to the ELF-to-plasma clearance, i.e. $\left(\mathrm{Cl}_{\text {out }}+\mathrm{Cl}_{\text {dif }}\right) / \mathrm{Cl}_{\text {dif. }}$ Considering that levofloxacin intracellular accumulation into macrophages was reported to be low and intermediate between those of ciprofloxacin and moxifloxacin (Seral et al., 2005), a systematic overestimation of levofloxacin concentrations in ELF due to a potential lysis of alveolar macrophages (Gontijo et al., 2014) was excluded. The $\mathrm{Cl}_{\text {out }}$ term may therefore characterize a 
Table 1

Pharmacokinetic parameter estimates of exposure.

\begin{tabular}{|c|c|c|c|c|}
\hline $\begin{array}{l}\text { Pharmacokinetic parameters for } \\
\text { levofloxacin }\end{array}$ & $\begin{array}{l}\text { Intravenous } \\
\text { solution }\end{array}$ & $\begin{array}{l}\text { Intratracheal aerosolized } \\
\text { solution }\end{array}$ & $\begin{array}{l}\text { Intratracheal chitosan microsphere } \\
\text { aerosolized powder }\end{array}$ & $\begin{array}{l}\text { Intratracheal PLGA microsphere } \\
\text { aerosolized powder }\end{array}$ \\
\hline Levofloxacin dose $(\mathrm{mg} / \mathrm{kg})$ & 5 & $5.79 \pm 0.5$ & $4.73 \pm 2.0^{\mathrm{a}}$ & $3.06 \pm 1.5^{\mathrm{a}}$ \\
\hline Plasma total ${ }^{\mathrm{b}} \mathrm{AUC}_{0.5}-\mathrm{t}$ (h.mg/L) (CV) & $1.33(0 \%)$ & $1.55(12 \%)$ & $0.90(19 \%)$ & $1.05(21 \%)$ \\
\hline Plasma unbound $\mathrm{AUC}_{0.5-\mathrm{t}}(\mathrm{h} \cdot \mathrm{mg} / \mathrm{L})(\mathrm{CV})$ & $0.73(0 \%)$ & $0.85(12 \%)$ & $0.49(19 \%)$ & $0.57(21 \%)$ \\
\hline $\mathrm{ELF} \mathrm{AUC}_{0.5-\mathrm{t}}(\mathrm{h} \cdot \mathrm{mg} / \mathrm{L})(\mathrm{CV})$ & $1.51(56 \%)$ & $1.73(112 \%)$ & $1.11(186 \%)$ & $167(104 \%)$ \\
\hline ELF-to-plasma total $\mathrm{AUC}_{0.5}-\mathrm{t}$ ratios $(\mathrm{CV})$ & $1.14(56 \%)$ & $1.21(106 \%)$ & $1.26(180 \%)$ & $169(97 \%)$ \\
\hline ELF-to-plasma unbound $\mathrm{AUC}_{0.5}-\mathrm{t}$ ratios $(\mathrm{CV})$ & $2.08(56 \%)$ & $2.23(106 \%)$ & $2.31(180 \%)$ & $311(97 \%)$ \\
\hline
\end{tabular}

a Dose estimated by weighing the powder insufflator before and after the dosing.

b Corresponding to free and protein-bound levofloxacin.

levofloxacin efflux transport mechanism as previously reported in vitro (Brillault et al., 2010) and in vivo (Zimmermann et al., 2015). However, as predicted by in vitro permeability studies on a Calu-3 lung epithelial model (Brillault et al., 2010) the impact of efflux transport was modest compared to what was reported with moxifloxacin, and the $\mathrm{Cl}_{\text {out }}$ value estimated for levofloxacin $(11.8 \mathrm{ml} / \mathrm{h} / \mathrm{kg})$ was much lower than the one estimated for moxifloxacin (57.1 ml/h/kg Gontijo et al. (2014)).

At the first sampling time point ( $30 \mathrm{~min}$ ) after intratracheal aerosolization of the chitosan microsphere powder (Fig. 4c), plasma and ELF concentrations were similar. Considering that levofloxacin was shown in vitro to be almost immediately released from the chitosan microspheres (Gaspar et al., 2015) and was predicted by the pharmacokinetic model to be immediately released into the ELF compartment after intratracheal administration (Fig. 1), the low bioavailability of levofloxacin compared to the intratracheal solution or to the PLGA microsphere powder was attributed to the loss of chitosan microsphere powder during the intratracheal administration step. During the administration with the insufflator the aerosol was indeed observed to be partly dispersed back into the environment. The ELF-to-unbound plasma $\mathrm{AUC}_{0.5 \text {-t }}$ ratio was above 2 (Table 1 ), in consistency with intravenous or intratracheal administrations of the levofloxacin solution. Therefore, the immediate release microspheres did not substantially differ, in terms of ELF concentration or systemic
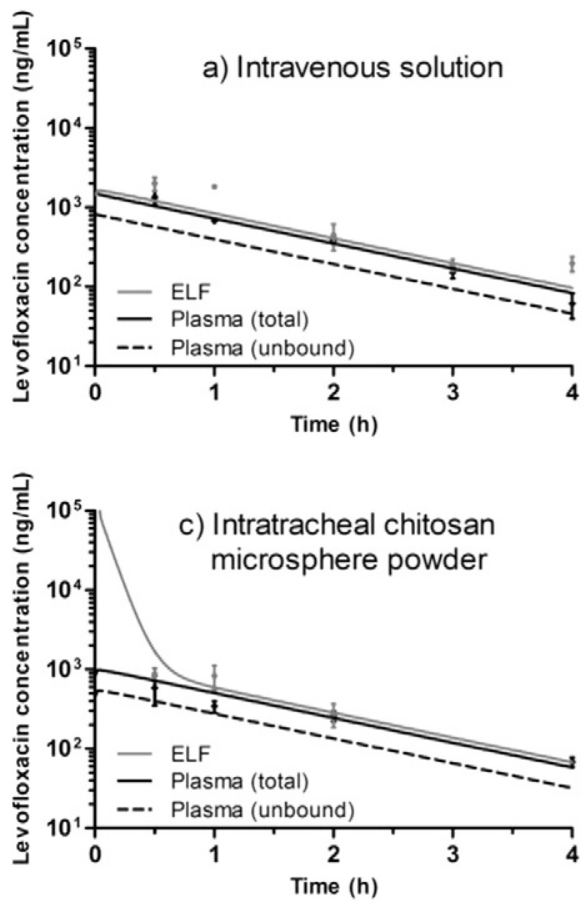

exposure to levofloxacin, from intravenous or aerosolized administration of the levofloxacin solution.

After intratracheal aerosolization of the levofloxacin-loaded PLGA microsphere powder (Fig. 4d), pharmacokinetic profiles dramatically differed from profiles obtained after intravenous or intratracheal administration of solutions or after the intratracheal administration of the chitosan microspheres. ELF concentrations were much higher than plasma concentrations, resulting in a high ELF-to-plasma $\mathrm{AUC}_{0.5}-\mathrm{t}$ ratio (Table 1). Moreover, plasma concentrations declined much more slowly than after intravenous administration or intratracheal aerosolization of the levofloxacin solution and could be measured up to $24 \mathrm{~h}$ versus $4 \mathrm{~h}$ after dosing. They declined in parallel to ELF concentrations with an approximate half-life of $18 \mathrm{~h}$ ( $v s .0 .96 \mathrm{~h}$ after intravenous administration), thus illustrating a flip-flop phenomenon. This flipflop observed in plasma corroborated the sustained release of levofloxacin in ELF that followed the intratracheal aerosolization of the levofloxacin-loaded PLGA microsphere powder. Such a result confirmed previous works where ELF concentrations that were modeled from plasma concentrations after intratracheal administration of sustained release rifampicin-loaded PLGA microspheres were predicted to be much higher than plasma concentrations (Doan et al., 2013). The bioavailability was $92 \%$, with $19 \%$ of the dose released immediately (burst release) into the ELF and 73\% released slowly over $>72 \mathrm{~h}$ into
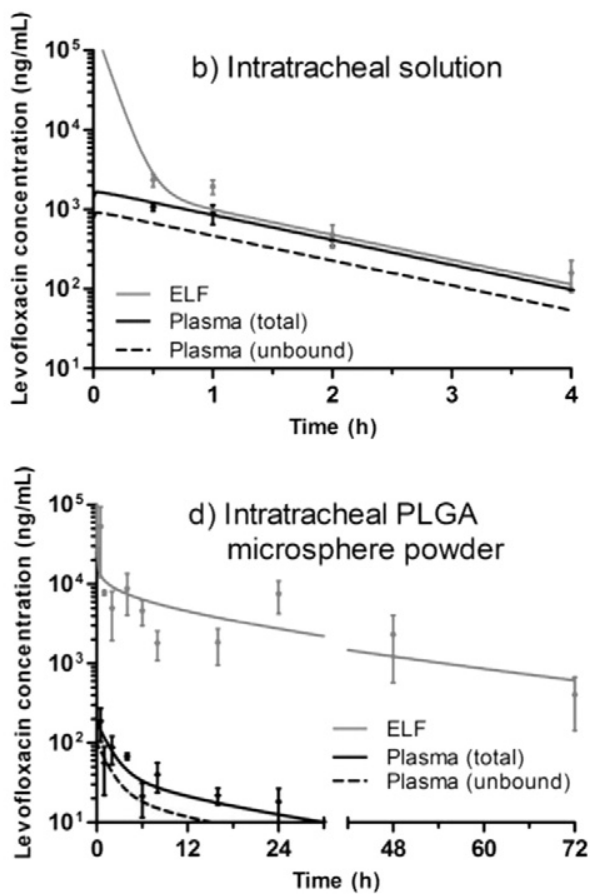

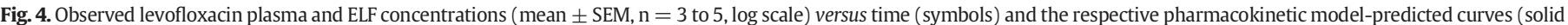

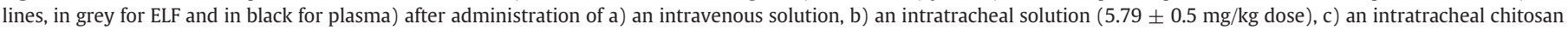

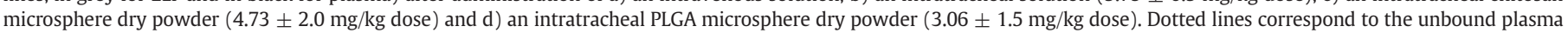
concentration curves. Note that in the intratracheal PLGA microspheres panel the abscissa (time) scale is different. 
the ELF from a depot compartment, the PLGA microspheres, according to a Weibull model ( $a=27.7 \mathrm{~h} ; b=0.817$ ). The in vivo release profile of levofloxacin from the PLGA microspheres that was estimated by the model is presented on Fig. 3 for comparison with the in vitro release profile. The "burst" release was lower in vivo than in vitro $\left(19 \%\left(=\mathrm{F}_{\mathrm{ELF}}=\right)\right.$ vs. $40 \%$ ). This difference may be explained by the fact that the in vitro release was performed in sink conditions under stirring and at constant $\mathrm{pH}$ (7.4), whereas in vivo levofloxacin saturation concentration may be reached rapidly due to the small volume of the ELF compartment (Fig. 1). Subsequently, the release became faster in vivo than in vitro. Beyond $18 \mathrm{~h}$, the cumulated in vivo released amount overpassed the in vitro results. Inhaled microspheres with diameter below $10 \mu \mathrm{m}$ are likely to be phagocytosed by lung macrophages (Hirota et al., 2013). The levofloxacin release from the PLGA microspheres may be impacted by the microsphere accumulation in intracellular compartments like phagolysosomes characterized by an acidic $\mathrm{pH}$ where levofloxacin is more soluble than at $\mathrm{pH}$ 7.4. In addition, in the case of the biodegradable polymeric PLGA microspheres, it is assumed that after the initial burst release the sustained release process results from the combination of drug diffusion within the polymer matrix and of the polymer matrix erosion (Shen and Burgess, 2012). The polymer erosion in vitro was demonstrated by SEM analysis (Fig. 2C and D). Polymer erosion may be faster in vivo than in vitro, thus explaining the higher levofloxacin amount released between 18 and $72 \mathrm{~h}$.

\section{Conclusions}

These results highlighted the benefit of using sustained-release microspheres administered as aerosols to maintain high pulmonary concentrations of a highly water soluble antibiotic characterized by a high permeability profile through the broncho-alveolar barrier, meanwhile promoting a comparatively low drug concentration in plasma. Further investigations are needed to clarify the fate of the microspheres (distribution, degradation rate etc.), to optimize the drug regimen (dose, frequency of administration), the degradation rate of the PLGA polymer and the levofloxacin content, and to address the issue of the toxicity of such a therapy towards the lungs in order to offer the patients a safe, easy-to-use and efficient levofloxacin sustained release dosage form for inhalation.

\section{Conflict of interest}

The authors report no conflict of interests.

\section{Acknowledgements}

The authors thank FCT (Fundação para a Ciência e a Tecnologia, Portugal) for MCG's financial support through grant SFRH/BD/80307/2011 and project PEst-OE/QUI/UI0313/2014, Dr. Carla Vitorino, University of Coimbra, for assistance with SEM, Mr. Julian Laroche, INSERM U 1070 and CHU de Poitiers, for the urea determinations, Ms. Agnès Audurier, INSERM U 1070 and Faculty of Medicine and Pharmacy, for her technical assistance, and Mr. Christophe Adier, INSERM U 1070 and CHU de Poitiers, for the Quality Management of the analytical process.

\section{References}

Anderson, J.M., Shive, M.S., 1997. Biodegradation and biocompatibility of PLA and PLGA microspheres. Adv. Drug Deliv. Rev. 28 (1), 5-24. http://dx.doi.org/10.1016/S0169409X(97)00048-3.

Beal, S.L., 2001. Ways to fit a PK model with some data below the quantification limit. J. Pharmacokinet. Pharmacodyn. 28 (5), 481-504.

Brillault, J., De Castro, W.V., Couet, W., 2010. Relative contributions of active mediated transport and passive diffusion of fluoroquinolones with various lipophilicities in a Calu-3 lung epithelial cell model. Antimicrob. Agents Chemother. 54 (1), 543-545. http://dx.doi.org/10.1128/aac.00733-09.
Bulitta, J.B., Bingölbali, A., Shin, B.S., Landersdorfer, C.B., 2011. Development of a new preand post-processing tool (SADAPT-TRAN) for nonlinear mixed-effects modeling in SADAPT. AAPS J. 13 (2), 201-211. http://dx.doi.org/10.1208/s12248-011-9257-x.

Díez, S., Tros de Ilarduya, C., 2006. Versatility of biodegradable poly(D,L-lactic-co-glycolic acid) microspheres for plasmid DNA delivery. Eur. J. Pharm. Biopharm. 63 (2), 188-197. http://dx.doi.org/10.1016/j.ejpb.2006.03.007.

Doan, T.V.P., Olivier, J.C., 2009. Preparation of rifampicin-loaded PLGA microspheres for lung delivery as aerosol by premix membrane homogenization. Int. J. Pharm. 382 (1-2), 61-66. http://dx.doi.org/10.1016/j.ijpharm.2009.08.008.

Doan, T.V., Couet, W., Olivier, J.C., 2011. Formulation and in vitro characterization of inhalable rifampicin-loaded PLGA microspheres for sustained lung delivery. Int. J. Pharm. 414 (1-2), 112-117. http://dx.doi.org/10.1016/j.ijpharm.2011.05.007.

Doan, T.V.P., Grégoire, N., Lamarche, I., Gobin, P., Marchand, S., Couet, W., et al., 2013. A preclinical pharmacokinetic modeling approach to the biopharmaceutical characterization of immediate and microsphere-based sustained release pulmonary formulations of rifampicin. Eur. J. Pharm. Sci. 48 (1-2), 223-230. http://dx.doi.org/10.1016/ j.ejps.2012.10.024.

EMA, 2015. Quinsair - Summary of Product Characteristics. European Medicines Agency, Science Medicines Health (http://ec.europa.eu/health/documents/communityregister/2015/20150326130815/anx_130815_en.pdf. Accessed 26 October 2015).

Feng, T., Tian, H., Xu, C., Lin, L., Xie, Z., Lam, M.H.-W., et al., 2014. Synergistic co-delivery of doxorubicin and paclitaxel by porous PLGA microspheres for pulmonary inhalation treatment. Eur. J. Pharm. Biopharm. 88 (3), 1086-1093. http://dx.doi.org/10.1016/j. ejpb.2014.09.012.

Foundation, C.F., 2015. Drug Development Pipeline Accessed 27 October 2015.

Gagnadoux, F., Pape, A.L., Lemarie, E., Lerondel, S., Valo, I., Leblond, V., et al., 2005. Aerosol delivery of chemotherapy in an orthotopic model of lung cancer. Eur Respir J. 26 (4), 657-661.

Gaspar, M.C., Couet, W., Olivier, J.C., Pais, A.A.C.C., Sousa, J.J.S., 2013. Pseudomonas aeruginosa infection in cystic fibrosis lung disease and new perspectives of treatment: a review. Eur. J. Clin. Microbiol. Infect. Dis. 32 (10), 1231-1252. http://dx.doi.org/10. 1007/s10096-013-1876-y.

Gaspar, M.C., Sousa, J.J.S., Pais, A.A.C.C., Cardoso, O., Murtinho, D., Serra, M.E.S., et al., 2015. Optimization of levofloxacin-loaded crosslinked chitosan microspheres for inhaled aerosol therapy. Eur. J. Pharm. Biopharm. 96, 65-75. http://dx.doi.org/10.1016/j. ejpb.2015.07.010.

Geller, D.E., 2009. Aerosol antibiotics in cystic fibrosis. Respir. Care 54 (5), 658-670.

Geller, D.E., Flume, P.A., Staab, D., Fischer, R., Loutit, J.S., Conrad, D.J., 2011. Levofloxacin inhalation solution (MP-376) in patients with cystic fibrosis with Pseudomonas aeruginosa. Am. J. Respir. Crit. Care Med. 183 (11), 1510-1516. http://dx.doi.org/10. 1164/rccm.201008-12930C.

Gontijo, A.V.L., Brillault, J., Grégoire, N., Lamarche, I., Gobin, P., Couet, W., et al., 2014. Biopharmaceutical characterization of nebulized antimicrobial agents in rats: 1. Ciprofloxacin, moxifloxacin, and grepafloxacin. Antimicrob. Agents Chemother. 58 (7), 3942-3949. http://dx.doi.org/10.1128/aac.02818-14.

Govender, T., Stolnik, S., Garnett, M.C., Illum, L., Davis, S.S., 1999. PLGA nanoparticles prepared by nanoprecipitation: drug loading and release studies of a water soluble drug. Journal of Controlled Release. 57 (2), 171-185. http://dx.doi.org/10.1016/S01683659(98)00116-3.

Hirota, K., Kawamoto, T., Nakajima, T., Makino, K., Terada, H., 2013. Distribution and deposition of respirable PLGA microspheres in lung alveoli. Colloids Surf. B: Biointerfaces 105, 92-97. http://dx.doi.org/10.1016/j.colsurfb.2012.12.027.

Hoppentocht, M., Hagedoorn, P., Frijlink, H.W., de Boer, A.H., 2014. Developments and strategies for inhaled antibiotic drugs in tuberculosis therapy: a critical evaluation. Eur. J. Pharm. Biopharm. 86 (1), 23-30. http://dx.doi.org/10.1016/j.ejpb. 2013.10.019.

Hurtado, F.K., Weber, B., Derendorf, H., Hochhaus, G., Dalla, C.T., 2014. Population pharmacokinetic modeling of the unbound levofloxacin concentrations in rat plasma and prostate tissue measured by microdialysis. Antimicrob. Agents Chemother. 58 (2) 678-686. http://dx.doi.org/10.1128/aac.01884-13.

King, P., Lomovskaya, O., Griffith, D.C., Burns, J.L., Dudley, M.N., 2010. In vitro pharmacodynamics of levofloxacin and other aerosolized antibiotics under multiple conditions relevant to chronic pulmonary infection in cystic fibrosis. Antimicrob. Agents Chemother. 54 (1), 143-148. http://dx.doi.org/10.1128/aac.00248-09.

Kirkby, S., Novak, K., McCoy, K., 2011. Aztreonam (for inhalation solution) for the treatment of chronic lung infections in patients with cystic fibrosis: an evidence-based review. Core Evidence 6, 59-66.

Koeppe, M.O., Cristofoletti, R., Fernandes, E.F., Storpirtis, S., Junginger, H.E., Kopp, S., et al. 2011. Biowaiver monographs for immediate release solid oral dosage forms: levofloxacin. J. Pharm. Sci. 100 (5), 1628-1636.

Marchand, S., Gobin, P. Brillault, J., Baptista, S., Adier, C. Olivier, J.-C., et al., 2010. Aerosol therapy with colistin methanesulfonate: a biopharmaceutical issue illustrated in rats. Antimicrob. Agents Chemother. 54 (9), 3702-3707. http://dx.doi.org/10.1128/aac 00411-10.

Ramazani, F., Chen, W., Van Nostrum, C.F., Storm, G., Kiessling, F., Lammers, T., et al., 2015 Formulation and characterization of microspheres loaded with imatinib for sustained delivery. Int. J. Pharm. 482 (1-2), 123-130. http://dx.doi.org/10.1016/j.ijpharm.2015. 01.043 .

Saelim, N., Suksawaeng, K., Chupan, J., Techatanawat, I., 2015. Biopharmaceutics classification system (BCS)-based biowaiver for immediate release solid oral dosage forms of moxifloxacin hydrochloride (moxiflox GPO) manufactured by the government pharmaceutical organization (GPO). Asian Journal of Pharmaceutical Sciences. http://dx. doi.org/10.1016/j.ajps.2015.11.016.

Sah, E., Sah, H., 2015. Recent trends in preparation of poly(lactide-co-glycolide) nanoparticles by mixing polymeric organic solution with antisolvent. J. Nanomater. 2015, 22. http://dx.doi.org/10.1155/2015/794601. 
Sawicki, G.S., Signorovitch, J.E., Zhang, J., Latremouille-Viau, D., von Wartburg, M., Wu, E.Q., et al., 2012. Reduced mortality in cystic fibrosis patients treated with tobramycin inhalation solution. Pediatr. Pulmonol. 47 (1), 44-52. http://dx.doi.org/10.1002/ppul. 21521.

Seral, C., Barcia-Macay, M., Mingeot-Leclercq, M.P., Tulkens, P.M., Van Bambeke, F., 2005. Comparative activity of quinolones (ciprofloxacin, levofloxacin, moxifloxacin and garenoxacin) against extracellular and intracellular infection by Listeria monocytogenes and Staphylococcus aureus in J774 macrophages. J. Antimicrob. Chemother. 55 (4), 511-517. http://dx.doi.org/10.1093/jac/dki059.

Shen, J., Burgess, D.J., 2012. Accelerated in vitro release testing methods for extended release parenteral dosage forms. J. Pharm. Pharmacol. 64 (7), 986-996. http://dx.doi. org/10.1111/j.2042-7158.2012.01482.x.

Stockmann, C., Sherwin, C.M.T., Ampofo, K., Spigarelli, M.G., 2014. Development of levofloxacin inhalation solution to treat Pseudomonas aeruginosa in patients with cystic fibrosis. Ther. Adv. Respir. Dis. 8 (1), 13-21. http://dx.doi.org/10.1177/ 1753465813508445.

Traini, D., Young, P.M., 2009. Delivery of antibiotics to the respiratory tract: an update. Expert Opinion on Drug Delivery. 6 (9), 897-905. http://dx.doi.org/10.1517/ 17425240903110710.

Zimmermann, E.S., Laureano, J.V., dos Santos, C.N., Schmidt, S., Lagishetty, C.V., de Castro, W.V., et al., 2015. A simultaneous semi-mechanistic population analysis of levofloxacin in plasma, lung and prostrate to describe the influence of efflux transporters on drug distribution following intravenous and intratracheal administration. Antimicrob. Agents Chemother. http://dx.doi.org/10.1128/aac.02317-15. 